\title{
Multi-Criteria Decision Making Approach for Flood Risk and Sediment Management in Koshi Alluvial Fan, Nepal
}

\author{
Mukesh Raj Kafle*, Narendra Man Shakya \\ Institute of Engineering, Pulchowk Campus, Lalitpur, Nepal \\ Email: *mkafle@pcampus.edu.np,nms@ioe.edu.np
}

How to cite this paper: Kafle, M.R. and Shakya, N.M. (2018) Multi-Criteria Decision Making Approach for Flood Risk and Sediment Management in Koshi Alluvial Fan, Nepal. Journal of Water Resource and Protection, 10, 596-619. https://doi.org/10.4236/jwarp.2018.106034

Received: May 9, 2018

Accepted: June 25, 2018

Published: June 28, 2018

Copyright (c) 2018 by authors and Scientific Research Publishing Inc. This work is licensed under the Creative Commons Attribution International License (CC BY 4.0).

http://creativecommons.org/licenses/by/4.0/

\section{c) (i) Open Access}

\begin{abstract}
This paper presents the results of multi-criteria decision-making (MCDM) approach for flood risk and sediment management in dynamic alluvial fan. The study is based on real problems of Koshi River, Nepal. Criteria weighting for each measure were estimated using Entropy, AHP and AHP-Entropy techniques. Preference ranking of alternatives was prioritized using MCDM methods-ELECTRE, TOPSIS and SAW. Five alternate measures for flood risk management and eight alternate measures for sediment control with seven evaluation criteria comprising economic, social, environmental and political aspects were taken into account. The Spearman's rank correlation coefficient between the criteria weighting techniques AHP and AHP-Entropy, Entropy and AHP-Entropy and AHP with Entropy were 0.964, 0.429 and 0.321 respectively. Preference ranks were determined using nine combinations of criteria weighting techniques and preference ranking methods. In the case of flood risk management, using of old Koshi channel was recommended as the highest prioritized solution. Similarly, for sediment control, reduction of upstream sediment supply was recommended as the top prioritized measures. The Euclidean distance test for each pairs of criteria weighting and prioritization methods showed all three MCDM methods of preference ranking were sensitive to weighting. On implementation of the recommended measures, local people of Sunsari, Saptari and Morang districts of Nepal will be highly benefited.
\end{abstract}

\section{Keywords}

Flood, Sediment, Prioritization, MCDM, Entropy, AHP, ELECTRE, TOPSIS, SAW

\section{Introduction}

Nepal is one of the worst flood-affected countries and frequently suffers from 
different kinds of water-induced disasters like landslides, debris flow, flooding and sedimentation. Most of the major rivers, which flow through Nepalese territory, are of snow fed characteristics and trans-boundary type. They originate from the Himalayas; flows through Siwaliks and Terai plain before crossing the Nepal-India border and are taken as the boon to these areas. However, during the monsoon season these rivers suffering from flash flooding become devastatingly hostile, cause damages to the infrastructures, farmland, settlements, and lives, and thereby become curse to these regions at the same time. Flood control in Nepal especially in the Terai region (Southern flat plain of Nepal) is a relatively recent issue. Until the middle of the past century natural forests covered the Terai and population was limited, also because of the malaria risks. After the eradication of malaria and the related deforestation the population density of the Terai increased substantially, amongst by the migration from hill tribes into the Terai. The forests were cut to allow for amongst others indigo plantations [1]. The increased rate of deforestation put the pressure for additional flood control measures.

The Koshi River is one of the major rivers in South Asia having snow fed characteristics. The Koshibasin is roughly located between $85^{\circ}$ to $89^{\circ}$ east longitude and $25^{\circ}$ to $29^{\circ}$ north latitude. The Koshi is a trans-boundary river, originating in Tibet, flowing through the Himalaya, through the eastern part of Nepal and the flat plain of Indian north territory [2]. The Koshi River, located on one of the most active alluvial fans in the world, poses major challenges in flood management and in coping with the excessive quantities of sediment entering the alluvial plain. The river formed an inland delta, a huge alluvial fan [3]. After 2008 disaster [3], sustainable flood risk management and sediment control in Koshi alluvial fan have been challenging issues.

Multi-criteria decision making (MCDM) is a decision support tool that describes a set of methods for structuring and evaluating alternatives on the basis of multiple criteria and objectives [4]. Three separate steps are utilized in MCDM models to obtain the ranking of alternatives: determine the relevant criteria and alternatives, attach weights to the criteria and numerical measures to the impacts of the alternatives on these criteria and finally process the numerical values to determine a ranking score of each alternative [5]. In the multi-criteria models the weights of criteria play a very significant role and they have different interpretations depending on context of decision making, on multi-criteria analysis methods [6]. Due to knowledge induced from the participation of several actors MCDM techniques can handle the inherent complexity and uncertainty of problems [7]. Mateo (2012a) describes MCDM as an advanced tool that can enhance the quality of decisions by making the process more explicitly rational and efficient leading to justifiable and explainable choices. Moreover, MCDM provides an adequate platform for stakeholders to communicate their personal preferences facilitates compromise and group decisions and promotes the role of participants in decision process as well [8]. The combinations of these characteristics enable the development of real participatory processes, which are crucial 
for the implementation of successful and long lasting flood management programs [9]. Since 1990s, MCDM has been successfully applied for the selection of best strategies of flood risk mitigation thus supporting for the optimization and allocation of available resources [10] [11] [12]. Recently, MCDM has also been applied to access the flood risk and coping capacity [13] [14] [15].

Since 1960s, dozens of MCDM techniques have been developed [16]. All the MCDM techniques are divided into concordance sub-group, compromising sub-group and scoring sub-group. Despite large number of MCDM methods, none is perfect and applicable to all decision problems. The selection of an appropriate tool will depend on the problem type and decision maker's objectives. Chistaz and Banihabib (2015) compared seven MCDM tools and concluded that ELECTRE III stood superior to select flood management options. Chung and Lee (2009) employed five methods and uncovered no clear methodological advantages to any of them. Apart from comparative studies, several researchers have combined two MCDM approaches to complement each other [17] [18] [19]. From the analysis of 128 peer-reviewed papers on multi-criteria decision making for flood risk management published from 1995 to 2015, Evers et al. (2016) concluded that AHP was the most popular method followed by TOPSIS and SAW. Based on the previous applications, objectives of the study and specific problems of the study area as well, Entropy, AHP and AHP-Entropy techniques are used for criteria weighting. Moreover, for preference ranking of alternatives, one method from each sub-group of MCDM methods is chosen. The selective methods include ELECTRE from the concordance sub-group; TOPSIS from compromising sub-group and SAW from the scoring sub-group. This paper aims to develop a methodology to prioritize alternative measures for flood risk management and sediment control in a dynamic alluvial fan with the MCDM approach.

The rest of this paper is structured in the following manner. A description of the study area is presented in Section 2. In Section 3, a brief review of materials and methods is provided. Section 4 summaries results. Analysis of results and discussion are dealt in Section 5. Finally, the conclusion is reported in section 7 followed by sensitivity analysis in Section 6 .

\section{The Koshi Alluvial Fan and Study Area}

The Koshi River is a trans-boundary river flowing through Tibet (China), Nepal and India. It is one of the largest tributaries of the Ganges River. The entire Koshi river basin has an area of $69,300 \mathrm{~km}^{2}$ up to its confluence with Ganges in India, out of which $29,400 \mathrm{~km}^{2}$ lies in China, $30,700 \mathrm{~km}^{2}$ in Nepal and $9200 \mathrm{~km}^{2}$ in India. The Koshi basin occupies eastern part of Nepal (Figure 1).

Koshi River in Nepal has seven major tributaries: Sunkoshi, Tamakoshi, Dudhkoshi, Indrawati, Likhu, Arun and Tamor. At Barahkshetra in Nepal it emerges from mountains and becomes the Koshi River. After flowing another 58 $\mathrm{km}$ it crosses into Bihar (India) near Bhimnagar and after another $260 \mathrm{~km}$ joins 


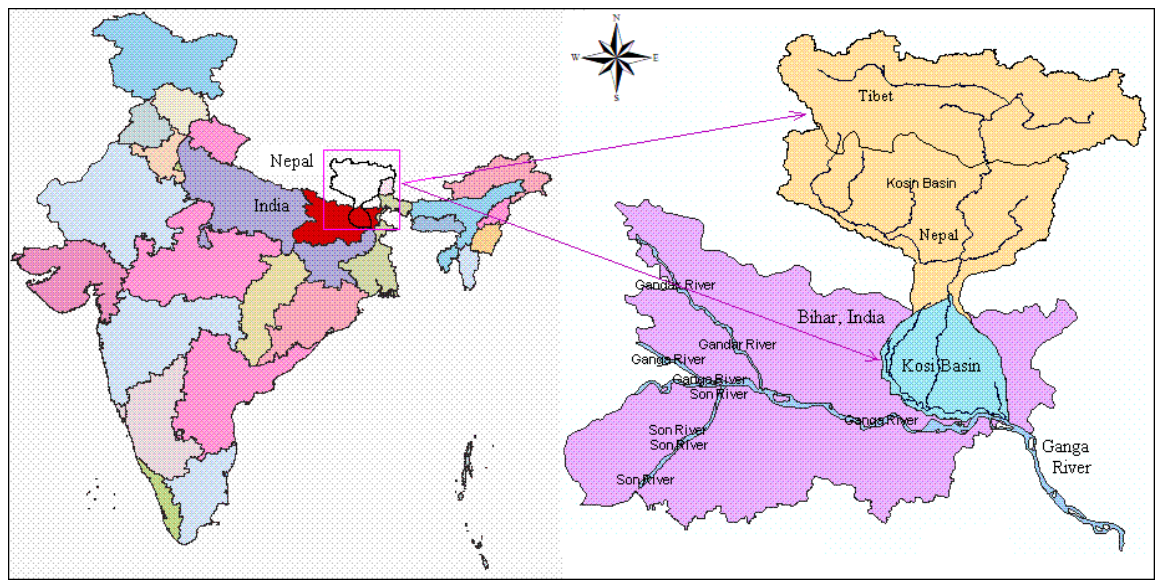

Figure 1. Index map of Koshi basin (Meera 2012).

the Ganges near Kursela. The river has a total length of $729 \mathrm{~km}$. The study area (Figure 2) is the Koshi alluvial fan in Nepal extending from Chatara to Koshi barrage having a stretch of around $50 \mathrm{~km}$.

The stretch between Chatara to Bhimnagar is steeply sloped. Downstream of Bhimnagar, the fan spreads out laterally with decreased slope having a radius of approximate $100 \mathrm{~km}$. The Koshi fan covers both Nepal and Indian territory (North Bihar) extending to an area of about $11,000 \mathrm{~km}^{2}$. The Koshi alluvial fan is flat country like any other floodplain with its apex at Chatara (Nepal). Over 200 years, as the result of avulsions, the river has shifted its course over $120 \mathrm{~km}$ from east to west (Figure 3). At present, the main channel of Koshi river is located at west of the fan. The river channel over the alluvial fan is highly unstable resulting strike of flood with little warning. Due to unstable characteristics of alluvial fan the flood can travel at high speeds carrying large amounts of sediments and debris. The process of dying and emerging new channels within the alluvial fan is active. The study reach can be described as a braided channel containing many islands both large and small. On the alluvial fan, the Koshi shows different channel patterns. The first $100 \mathrm{~km}$ downstream from Chatara the river is braided. The river is meandering for last around $160 \mathrm{~km}$ at toe of the fan.

Annual rainfall in the Koshi plains is spatially distributed ranging from 1000 $\mathrm{mm}$ to $1600 \mathrm{~mm}$. The average annual discharge at Chatara hydrological station (station no. 695) is recorded $1800 \mathrm{~m}^{3} / \mathrm{s}$. At Chatara, total annual sediment load is estimated 100 million $\mathrm{m}^{3}$, out of which 60 million $\mathrm{m}^{3}$ is bed load and suspended load and rest 40 million $\mathrm{m}^{3}$ is considered wash load. Approximately 30 - 40 million $\mathrm{m}^{3}$ of sediment load is presumed to be deposited annually between Chatara to Kursela [20].

\section{Materials and Methods}

\subsection{Alternative Measures}

Long-term visions of flood management strategies are the starting point to reduce the problems of Koshi River system. Both structural and non-structural 


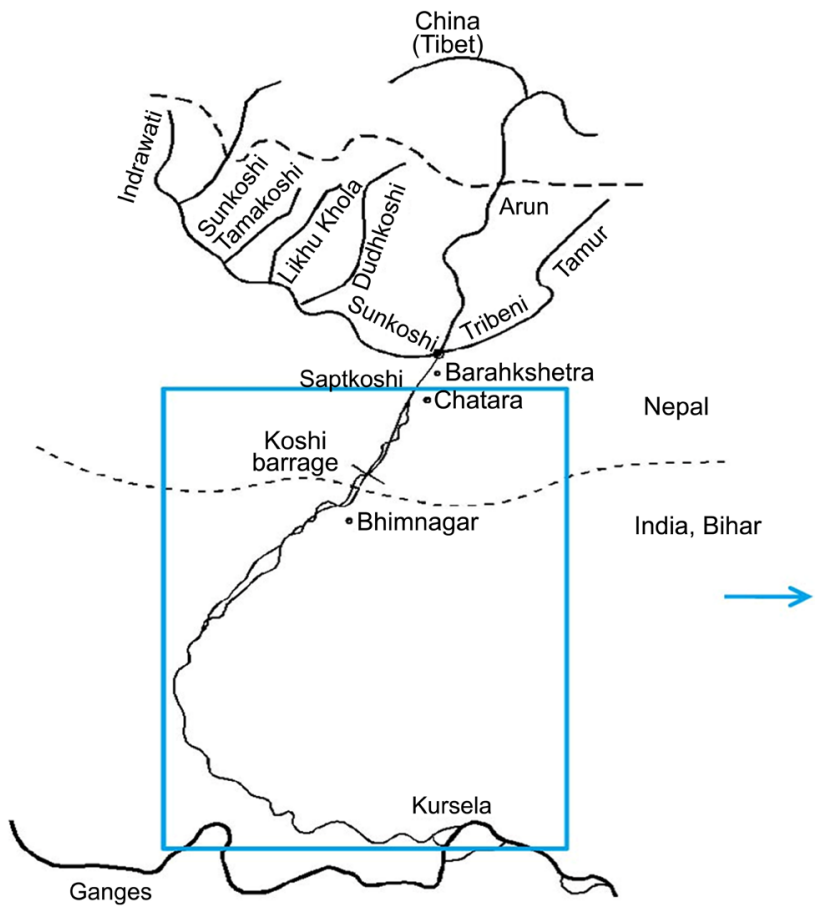

Figure 2. Koshi alluvial fan (Hooning 2011).

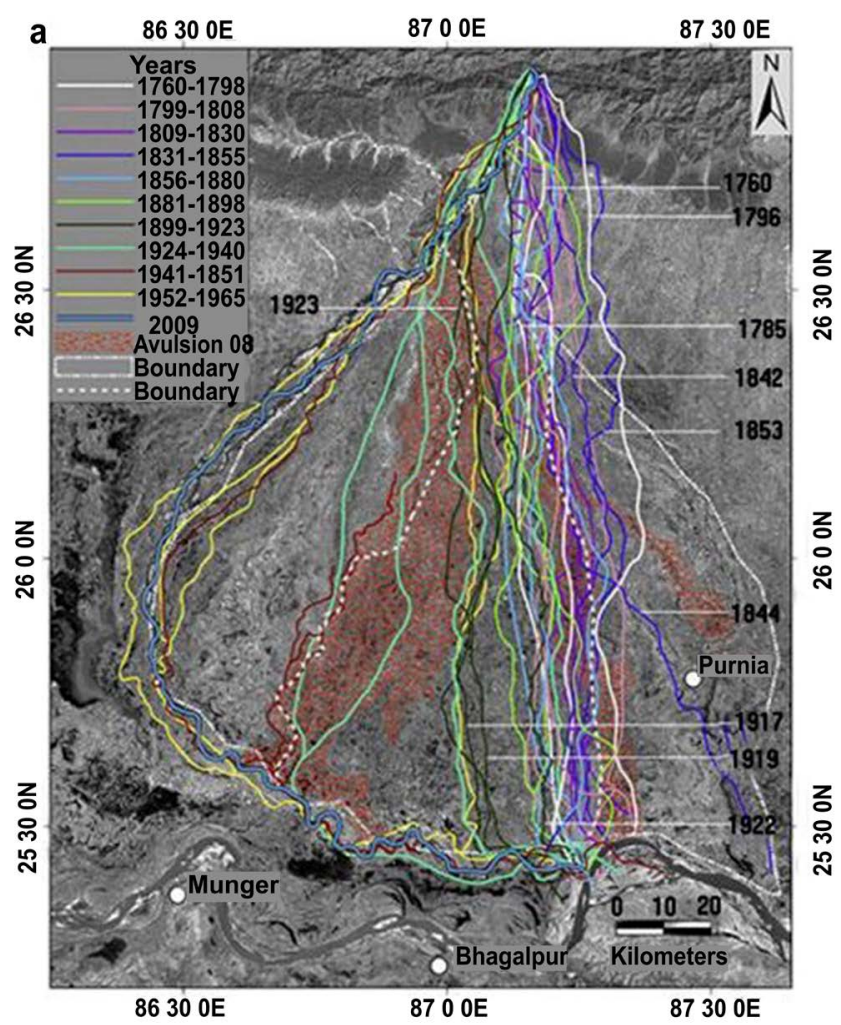

Figure 3. Different courses of Koshi River over time (Chakraborty et al. 2009).

flood risk management are the part of these management strategies. This study focuses on solutions of flood risk management incorporating both permanent 
and recurrent measures. The solutions are based on previous studies [3] focused on hydraulic and morphological processes and sediment management as well. Some alternatives are common for both measures. The alternatives on hydraulic measures and sediment control measures are presented in tabular form (Table $1)$.

\subsection{Hydraulic Measures}

\subsubsection{Increasing the Height of Embankments over Time (Q1)}

In this measure, the height of the embankments is designed to increase over time, following the increase of bed level and flood levels of the Koshi River as in Yelow River in China (Figure 4). However, this process will continue over the years, resulting in an elevated river; the riverbed is a couple of metres higher than the surrounding area. This measure requires only small extra area; just increasing heights and width of the embankments. Development of forest might strengthen existing channels. This measure doesn't impact adversely in Ne$\mathrm{pal} /$ India cooperation. However, there is very large risk of consequences of flooding on breaching the embankments.

\subsubsection{Sleeper Dikes (Q2)}

In this measure, a second line of defence (dark black line) is constructed as sleeper dikes (Figure 5). The existing red line along the bank represent existing embankment and blue colour represents the water body in river channel in low flow season. If an embankment breaches, the second dike ring prevents large flooding. The merits of this intended solution are: limited inundation area and creation of more space for sediment deposition. However, this measure requires expropriation of land at both sides over a width of around $200 \mathrm{~m}$. In addition, it takes many years for the completion of construction resulting the displacement of bridges and other existing structures.

Table 1. List of alternative measures.

\begin{tabular}{|c|c|c|}
\hline \multicolumn{3}{|c|}{ Alternatives } \\
\hline Hydraulic measures & S.N & Sediment control measures \\
\hline $\begin{array}{l}\text { Increasing the height of embankments } \\
\text { over time (Q1) }\end{array}$ & 1 & Reduction of supply of sediments ( $\mathrm{S} 1$ ) \\
\hline Sleeper dikes (Q2) & 2 & Koshi high dam (S2) \\
\hline The use of an old Koshi course (Q3) & 3 & $\begin{array}{l}\text { Narrowing of the river with permanent struc- } \\
\text { tures (S3) }\end{array}$ \\
\hline Controlled flooding, flood storage (Q4) & 4 & $\begin{array}{l}\text { Narrowing of the river with recurrent } \\
\text { measures (S4) }\end{array}$ \\
\hline \multirow[t]{4}{*}{ Koshi high dam (Q5) } & 5 & Dredging (S5) \\
\hline & 6 & Controlled flooding using old course (S5) \\
\hline & 7 & Controlled flooding with storage areas (S6) \\
\hline & 8 & Removing embankments and Koshi barrage (S7) \\
\hline
\end{tabular}




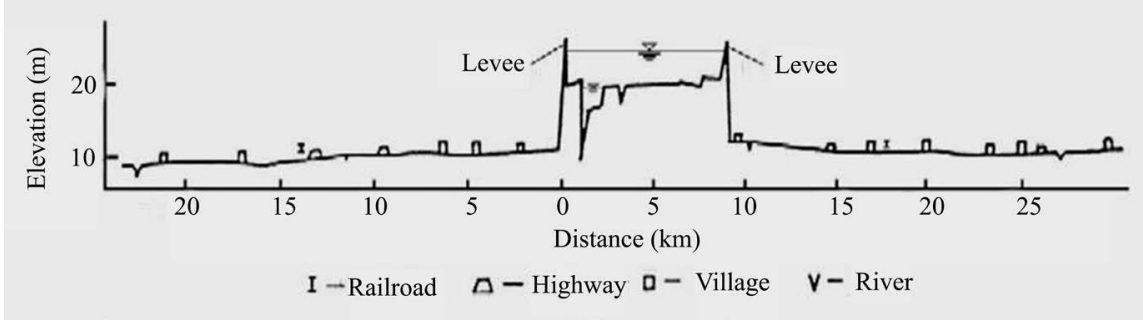

Figure 4. Raising embankments of the Yellow River (Baosheng Wu 2007).

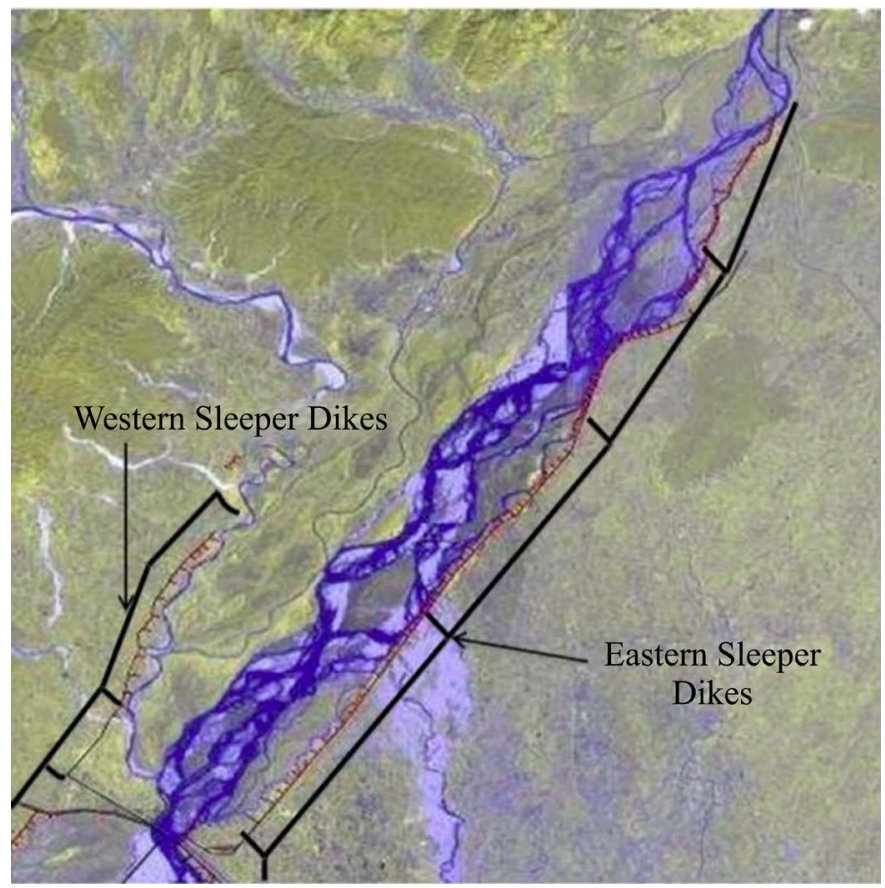

Figure 5. Proposed Sleeper dikes.

\subsubsection{Use of an Old Koshi Course (Q3)}

In this intended solution, the flood peak is lowered by extracting discharge by the use of an old course during the flood (Figure 6). Construction of hydraulic structure is required to regulate this process. The courses of former channels define the possible location for this regulating structure. This measure reduces discharge in downstream resulting smaller loads in embankments. This helps people to be prepared and location of inundation is known. The demerits of this measure are: requirement of hydraulic structure of around $250 \mathrm{~m}-300 \mathrm{~m}$ wide to open bifurcation channel, additional construction of bridges along highway, additional construction of embankments along the old course, acquirement of large agriculture land, protection of bank erosion and deposition of large sediment between embankments along the old course.

\subsubsection{Controlled Flooding, Flood Storage (Q4)}

In this measure, the flood peak is supposed to be lowered by extracting discharge using selected and prepared inundation areas (Figure 7). Construction of new hydraulic structure is needed or a part of the embankment needs to be destroyed 


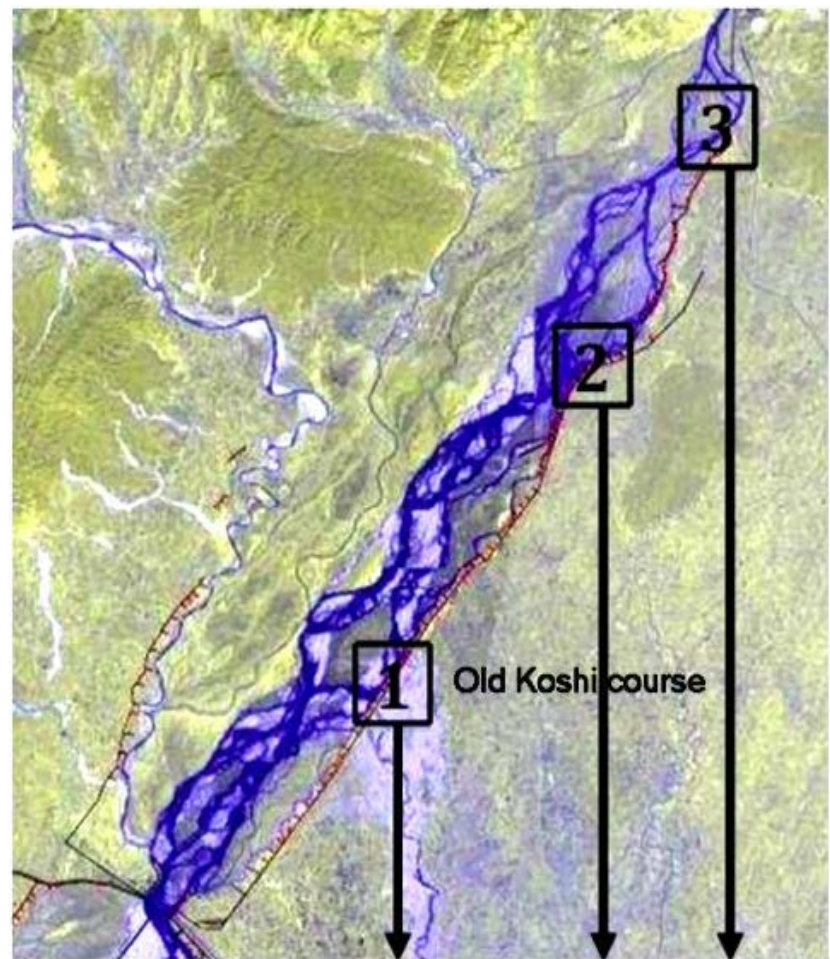

Figure 6. Possible locations of using old Koshi course.

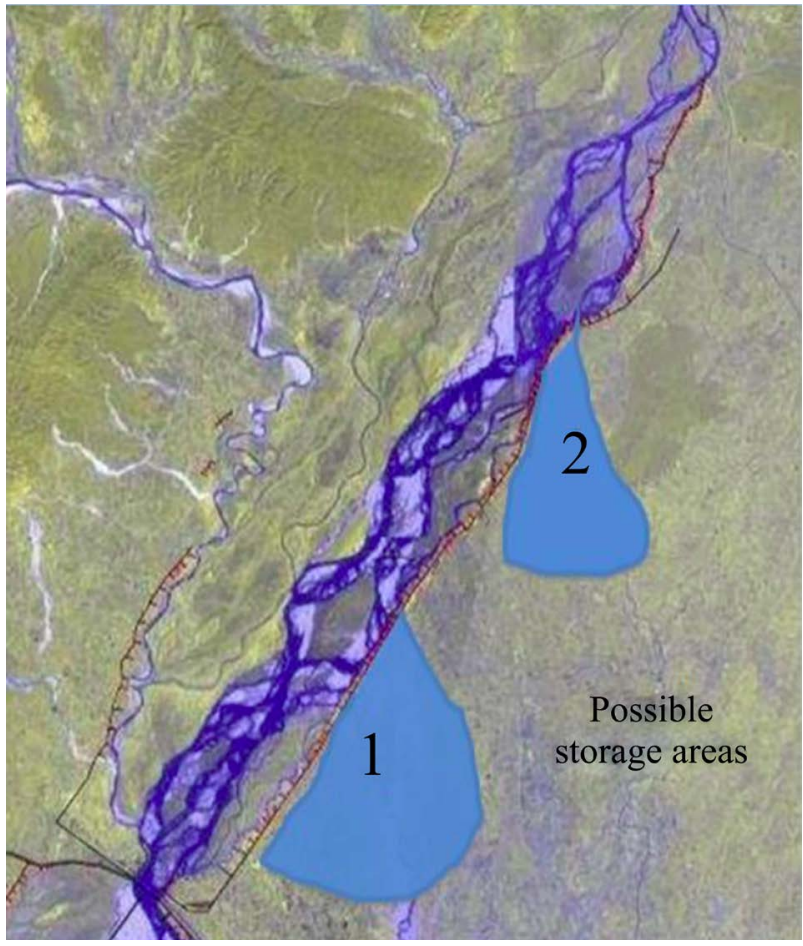

Figure 7. Proposed flood storage areas.

and rebuilt later on. Merits of this intended solution are the reduction of discharge downstream, which results in smaller loads on the embankments, and people are prepared with known location of inundation. However, it requires 
construction of levees around villages and there is risk to destroy other levee by people to protect their own land.

\subsubsection{Koshi High Dam (Q5)}

In this measure, a high dam is constructed, located somewhere between Tribeni and Chatara, to control the floods (Figure 8). The discharge of the river is controlled; flood peak can be lowered. Such a dam can be used for hydropower as well. This solution works fast after the dam is constructed. However, it is supposed of taking long time before the project can be realized. People around 75 thousand who live upstream the dam have to be resettled due to reservoir inundation. In the downstream side, the ground water level drops, which may cause problems for the farmers. Existing Sunsari-Morang irrigation facilities gets less water. It is very expensive solution.

\subsection{Sediment Control Measures}

\subsubsection{Reduction of Upstream Supply of Sediments (S1)}

The different regions including the high Himalaya, Mountains, Siwaliks and Terai which the Koshi River passes (Figure 9) contribute to the high sediment load. In the high Himalaya region, moraine dammed glacier lakes are common and can result in catastrophic floods when moraines are breached. In the High Mountains region, the rocks are resistant to weathering. All valleys in this region were glaciated. Active river cutting enhanced by high river gradients has resulted in very deep canyons being carved since glaciations. The Middle Mountains are present north of the Siwaliks. The Koshi River is down-cutting this area. Mass wasting (rock falls and landslides) is present. The Siwaliksregions possess steep

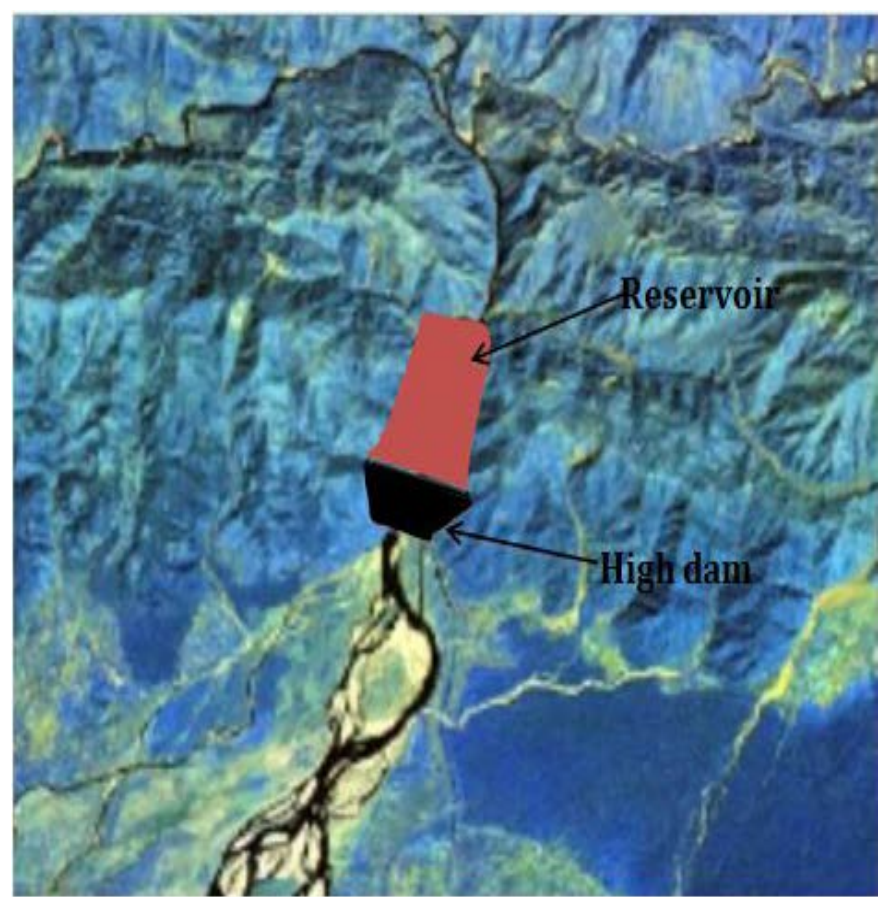

Figure 8. Proposed high dam. 


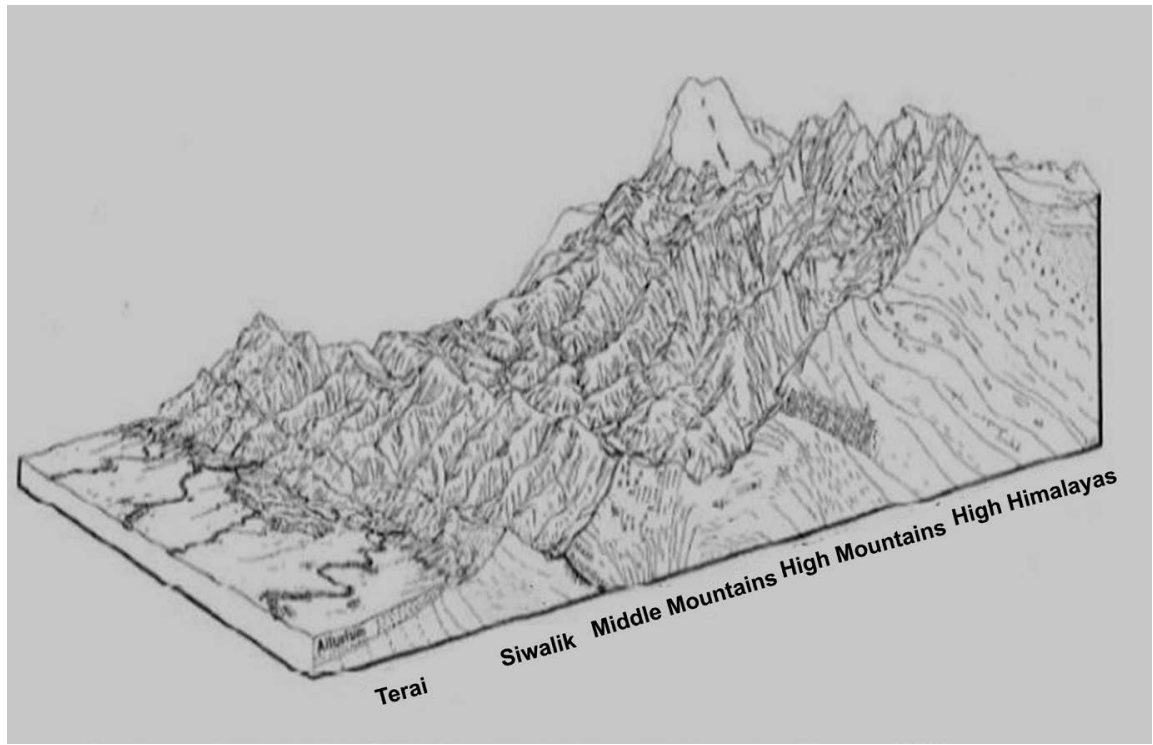

Figure 9. The physiographic regions of Nepal (Galay 1987).

slopes and weakly consolidated layers of bedrock, subject to severe surface erosion. High intensity rainfall produces high erosion and torrent flows. Mass wasting is exceptionally high throughout the Siwalik. The Terai region is the flat land as in Figure 9. It consists of gently sloping recently deposited alluvium. The soil is sandy. In the Terai, there is primarily sediment deposition.

Possible measures to reduce such sediment supply are bottom or bank protection; check dams and reforestation to decrease the supply of sediment at its origin. The processes which are responsible for the high sediment load of the river i.e. landslides, bank and bottom erosion and GLOFs, have to be reduced.

\subsubsection{Koshi High Dam (S2)}

This alternative is common to hydraulic measures (Figure 8). The high dam traps the sediment transported by the Koshi. Downstream of the dam, the aggrading riverbed changes into a degrading one.

\subsubsection{Narrowing of the River with Permanent Structures (S3)}

In this measure, permanent structures are constructed narrowing the river to close off channels (Figure 10). The higher flow velocities resulted from reducing the flow area by narrowing the river the sediment load is transported over longer distances. In Nepal side, this solution may provide more spaces for people and more agriculture land may be reclaimed. However, problems are moved further downstream to India side. It is costlier and lots of maintenance work is needed. It may be temporary solution because of downstream sedimentation. Indian side may be reluctant to implement this solution.

\subsubsection{Narrowing of the River, but with Recurrent Measures (S4)}

In this measure, certain channels are closed off and the river is narrowed by recurrent river training measures (Figure 11). The narrowing will induce higher 


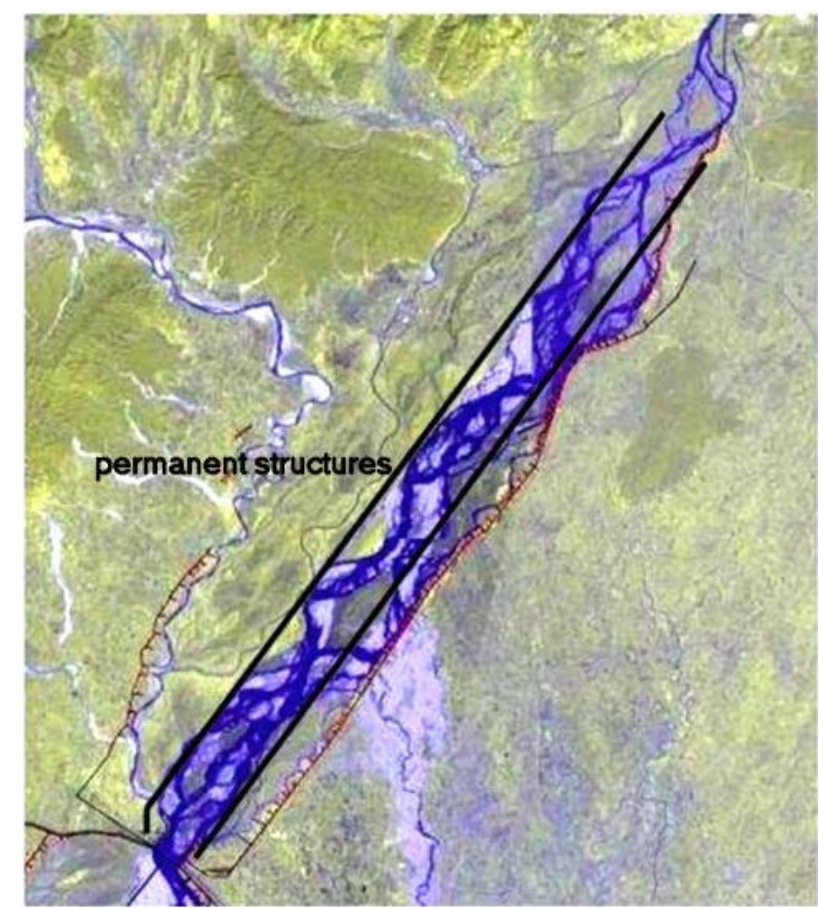

Figure 10. Proposed permanent structures narrowing the river.

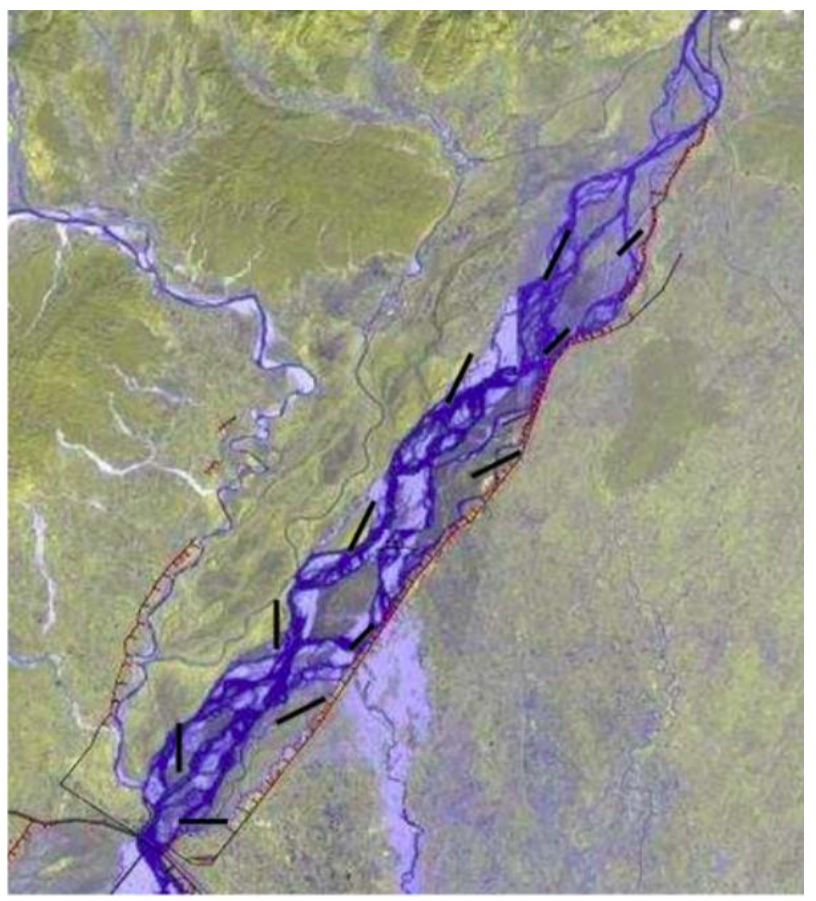

Figure 11. Proposed recurrent measures narrowing the river.

flow velocities and the sediment load is transported over longer distances. The channels are also diverted away from the embankments. This solution isn't so expensive. It's a flexible application, learning by doing. There may uncertainty about effectiveness and may be risk of bypassing. Experienced people are needed for effective implementation. 


\subsubsection{Dredging (S5)}

In this measure, annual deposited sediment between Chatara to the Koshi barrage is dredged and deposited elsewhere thus maintaining the riverbed at a constant level. The merit of this measure is that it is workable and has no impact on nature. Only the deposited sediments of around 20 million $\mathrm{m}^{3}$ have to be dredged annually. Managing the space to store the dredged sand is a big challenge. It is expensive and spending huge amount annually may be difficult for local authority.

\subsubsection{Controlled Flooding, Using Old Course (S6)}

In this measure, discharge and sediment are extracted out of the embanked system and flushed away by the use of an old course in high discharge (Figure 6). A hydraulic structure is proposed to regulate this process. The location of this measure should be just upstream of the barrage, to flush as much sand as possible.

\subsubsection{Controlled Flooding with Storage Areas (S7)}

In this measure, water and sediment are temporarily stored with regulating system in low areas (Figure 7). Hydraulic structures, such as an inlet with levees, compartmentalization with levees, have to be built. A warning system is needed and consensus with the local people has to be reached for effective implementation.

\subsubsection{Removing Embankments and the Koshi Barrage (S8)}

In this measure, embankments and the Koshi barrage are supposed to be removed without regulation of the Koshi River. Additional measures should be taken to build shelter areas, raising villages or construct embankments around villages thus marking valuable or less valuable areas and to sacrifice the less valuable areas in case of a flooding or an avulsion. This solution provides a lot of space for sediment deposition resulting the formation of inland delta. No disaster on the scale of 2008 flood is envisaged. However, many smaller floods over the alluvial fan may cause big damage. Removing of embankments will cause instant flooding. Indian government may also be reluctant to implement this measure as Koshi barrage has helped to flood control during monsoon reducing the damage due to flood in northern Bihar, India.

\subsection{Evaluation Criteria}

Flood imposes destruction effects on social, ecological and economic environment and threatens sustainable development of flood prone areas. Flood management can be an integrated solution if social, environmental and economical instabilities of the region due to destruction of floods are controlled. So, each alternative should be evaluated with economic, technical, social and environmental aspects. In addition, in this particular case being a trans-boundary river and treaty between two sovereign government authorities, political cooperation is also considered a criterion. Based on stakeholder's opinion, the considered 
criteria are discussed briefly as below:

1) Costs: It includes design, construction, maintenance and expropriating of land costs as well.

2) Technical complexity: Feasibility of the solution is analyzed under these criteria. If it is very complex the uncertainty and risk of failure of intended solution presumed to be increased resulting unfeasible solution.

3) Social impact: This criterion indicates safety of the local people and impact on society thus reducing the risk of flooding under the implementation of intended solution as both for short and long term solution.

4) Time for implementation: This criterion discusses the required time of implementation of the intended solution for its effectiveness.

5) Environmental impact: This criterion deals with the impact of intended solution on environment especially focusing on influence of intended solution to local people, their lives, land and displacements if any. It also covers impacts on the flora and fauna after the implementation of intended solution.

6) Impact on irrigated area: This criterion covers the impact on existing irrigation facilities especially head works, canals under Morang-Sunsari irrigation project which currently serving thousands of hectares of command area both in Nepal and India.

7) Cooperation with India: -being a trans-boundary river both governments of India and Nepal have signed a treaty on Koshi River in 1953. For the implementation of any intended solution needs cooperation in political level between both government authorities.

\subsection{Methodology}

The methodology of this study is basically formulated in the sequences of criteria weighting, preference ranking of alternatives and recommendation of optimal alternatives with established MCDM techniques. Based on advantages and disadvantages, stakeholder's opinion, each criteria are valued in very positive $(+++)$ to very negative (---). Indicators for each alternative and criteria for both hydraulic measures and sediment control measures are summarized in Table 2. Weighting indexes are estimated using Entropy, AHP, and the combination Entropy and AHP techniques. Shannon's Entropy is a well-known method in obtaining the weights for MCDM problems especially when obtaining a suitable weight based on the preferences and decision-making experiments are not possible. Analytic hierarchy process method (AHP) proposed by Saaty (1980) is the proven subjective method for determining weight. When applying the AHP, the preferences of the decision criteria are compared in a pairwise manner with regard to the criterion preceding them in the hierarchy. If two criteria are of equal importance, a value of 1 is given in the comparison, whereas a value of 9 indicates the absolute importance of one criterion over the other (Table 3). The weighting indexes for third technique i.e. combination of entropy and AHP are obtained using Equation (1). The preference ranking of alternatives for both 
Table 2. Proposed alternatives with criteria.

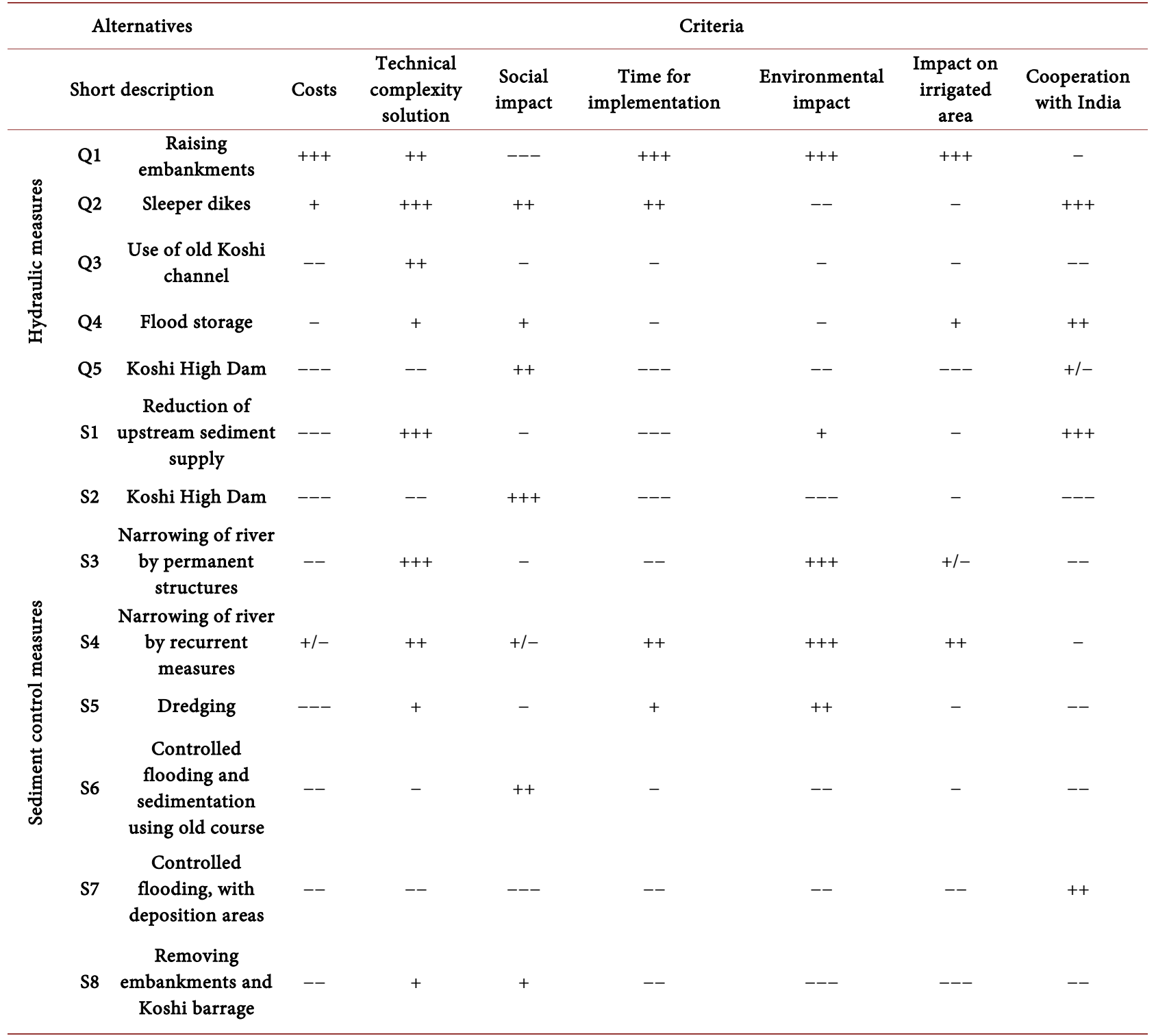

Table 3. The Saaty scale definition (Saaty 1980).

\begin{tabular}{cc}
\hline Definition & Intensity of Importance \\
\hline Equal Importance & 1 \\
Moderate Importance & 3 \\
Strong Importance & 5 \\
Very Strong Importance & 7 \\
Extreme Importance & 9 \\
Can be used to express intermediate values & $2,4,6,8$ \\
\hline
\end{tabular}

hydraulic measures and sediment control measures for all criteria weighting indexes estimated from entropy, AHP and combination of both are assessed by 
three MCDM methods-ELECTRE, TOPSIS and SAW. Results for combinations of criteria weighting techniques and preference ranking methods are averaged and final preference ranking is determined.

$$
w_{j}=\frac{v_{j} u_{j}}{\sum_{j=1}^{n} v_{j} * u_{j}}
$$

where, $w_{j}=$ final weight of the composition of Entropy and AHP, $v_{j}=$ Entropy weighting index, $u_{j}=$ AHP weighting index.

ELECTRE is a family of MCDM methods that originated in Europe and was first proposed by Bernard Roy in mid-1960s [21]. The acronym ELECTRE stands for Elimination and Choice Expressing Reality. It is an outranking method based on outranking relation and concordance analysis.

TOPSIS is a MCDM method originally developed by Hwang and Yoon in 1981 with further developments by Yoon in 1987, and Hwang, Lai and Liu in 1993 [22]. The acronym TOPSIS stands for the Technique for Order of Preference by Similarity to Ideal Solution. It is based on the concept that the chosen alternative should have the shortest geometric distance from the positive ideal solution and the longest geometric distance from the negative ideal solution [22]. It is a method of compensatory aggregation that compares a set of alternatives by identifying weights for each criterion, normalizing scores for each criterion and calculating the geometric distance between each alternative and the ideal alternative, which is the best score in each criterion.

SAW abbreviated for Simple Additive Weighting, which is also known as, weighted linear combination or scoring methods is a simple and most often used multi attribute decision technique. The method is based on the weighted average. It is one of the simplest methods of the MCDM methods [23]. An evaluation score is calculated for each alternative by multiplying the scaled value given to the alternative of that attribute with the weights of relative importance directly assigned by decision maker followed by summing of the products for all criteria (Table 4).

\section{Results}

\subsection{Preference Ranking of Alternatives}

Altogether nine combinations of criteria weighting and preference ranking MCDM methods are analyzed to prioritize alternatives for both hydraulic measures and sediment control measures and results are presented in tabular form (Table 5, Table 6).

From the final ranking of alternatives the preferred solutions for hydraulic measures can be prioritized as follow:

Q3 > Q5 > Q2 > Q4 > Q1

Where, AE-E = weighting by AHP and Entropy and preference ranking by ELECTRE method, AE-T = Weighting by AHP and Entropy and preference ranking by TOPSIS method, AE-S = Weighting by AHP and Entropy and 
Table 4. Score and weightage.

\begin{tabular}{cccccc}
\hline \multirow{2}{*}{ Indicator } & Score & Criteria & \multicolumn{3}{c}{ Weightage } \\
\cline { 4 - 6 } & & Entropy & AHP & AHP \& Entropy \\
\hline Positive (+) & 50 & Cost (C1) & 0.360 & 0.434 & 0.602 \\
$\begin{array}{c}\text { More positive (++) } \\
\begin{array}{c}\text { Very positive } \\
(+++)\end{array}\end{array}$ & 75 & Social impact (C2) & 0.383 & 0.225 & 0.333 \\
$\begin{array}{c}\text { Negative (-) } \\
\begin{array}{c}\text { More negative } \\
(--)\end{array}\end{array}$ & 40 & Technical complexity solution & 0.054 & 0.036 & 0.008 \\
$\begin{array}{c}\text { Very negative } \\
(---)\end{array}$ & 10 & Time for implementation (C4) & 0.043 & 0.147 & 0.024 \\
& & Environmental impact (C5) & 0.057 & 0.047 & 0.010 \\
& & Impact on irrigated area (C6) & 0.050 & 0.049 & 0.010 \\
\hline
\end{tabular}

Table 5. Final preference ranking (Hydraulic measures).

\begin{tabular}{|c|c|c|c|c|c|c|c|c|c|c|c|}
\hline \multirow{2}{*}{ Alternatives } & \multicolumn{9}{|c|}{ Combination of weightage and preference ranking methods } & \multirow{2}{*}{ Average } & \multirow{2}{*}{$\begin{array}{c}\text { Final } \\
\text { Preference } \\
\text { Rank }\end{array}$} \\
\hline & AE-E & $\mathrm{AE}-\mathrm{T}$ & AE-S & $\mathrm{EE}$ & ET & ES & $\mathrm{AE}$ & $\mathrm{AT}$ & AS & & \\
\hline Q1 & 2 & 5 & 5 & 2 & 5 & 4 & 3 & 5 & 5 & 4.00 & 5 \\
\hline Q2 & 2 & 4 & 3 & 2 & 2 & 1 & 3 & 4 & 3 & 2.67 & 3 \\
\hline Q3 & 2 & 1 & 2 & 2 & 1 & 3 & 1 & 1 & 2 & 1.67 & 1 \\
\hline Q4 & 1 & 3 & 4 & 1 & 3 & 5 & 1 & 3 & 4 & 2.78 & 4 \\
\hline Q5 & 2 & 2 & 1 & 2 & 4 & 2 & 3 & 2 & 1 & 2.11 & 2 \\
\hline
\end{tabular}

Table 6. Final preference ranking (Sediment control measures).

\begin{tabular}{|c|c|c|c|c|c|c|c|c|c|c|c|}
\hline \multirow{3}{*}{ Alternatives } & \multirow{2}{*}{\multicolumn{9}{|c|}{$\begin{array}{c}\text { Combination of weightage and preference ranking } \\
\text { methods }\end{array}$}} & \multirow{3}{*}{ Average } & \multirow{3}{*}{$\begin{array}{c}\text { Final } \\
\text { Preference } \\
\text { Rank }\end{array}$} \\
\hline & & & & & & & & & & & \\
\hline & AE-E & AE-T & AE-S & $\mathrm{EE}$ & ET & ES & $\mathrm{AE}$ & $\mathrm{AT}$ & AS & & \\
\hline S1 & 4 & 2 & 1 & 3 & 2 & 1 & 2 & 1 & 1 & 1.89 & 1 \\
\hline S2 & 1 & 4 & 7 & 3 & 5 & 7 & 4 & 4 & 4 & 4.33 & 5 \\
\hline S3 & 6 & 5 & 2 & 3 & 4 & 2 & 7 & 5 & 2 & 4.00 & 4 \\
\hline S4 & 6 & 1 & 3 & 1 & 1 & 3 & 7 & 2 & 3 & 3.00 & 2 \\
\hline S5 & 4 & 3 & 4 & 1 & 3 & 4 & 4 & 3 & 5 & 3.44 & 3 \\
\hline S6 & 3 & 6 & 6 & 3 & 6 & 6 & 1 & 7 & 7 & 5.00 & 6 \\
\hline S7 & 1 & 7 & 8 & 3 & 7 & 8 & 2 & 6 & 8 & 5.56 & 7 \\
\hline S8 & 6 & 8 & 5 & 3 & 8 & 5 & 4 & 8 & 6 & 5.89 & 8 \\
\hline
\end{tabular}

preference ranking by SAW method, EE = Weighting by Entropy and preference ranking by ELECTRE method, ET = Weighting by Entropy and preference ranking by TOPSIS method, ES = Weighting by Entropy and preference ranking by SAW method, AE = Weighting by AHP and preference ranking by ELECTRE method, AT $=$ Weighting by AHP and preference ranking by TOPSIS method, 
AS = Weighting by AHP and preference ranking by SAW method.

From the final ranking of alternatives the preferred solutions for sediment control measures can be prioritized as follow:

$$
\mathrm{S} 1>\mathrm{S} 4>\mathrm{S} 5>\mathrm{S} 3>\mathrm{S} 2>\mathrm{S} 6>\mathrm{S} 7>\mathrm{S} 8
$$

\section{Discussion}

Based on this study, it is evident that different alternative solutions of flood risk and sediment control measures of Koshi alluvial fan have different prioritization levels (Table 5). For flood control hydraulic measures, among nine combinations of criteria weighting and preference ranking methods, an alternate solution Koshi high dam (Q5) is first prioritized with combinations of criteria weighting methods AHP, AHP \& Entropy and preference ranking method SAW. However, combination of criteria weighting method Entropy and preference ranking method SAW prioritize sleeper dikes as first rank followed by Koshi high dam (Q5). In contrast, combination of all criteria weighting methods with preference ranking method ELECTRE results highest priority for floods storage (Q4) measure. Similarly, combination of all criteria weighting methods with preference ranking method TOPSIS list the alternate solution of using old Koshi channel (Q3) as the highest priority measure over others. The results show deviations on preference ranking with different methods. This may be due to variations in criteria weighting index. Considering average value of results for all nine set of combinations of criteria weighting techniques and preference ranking methods, an alternate solution of using old Koshi channel (Q3) is recommended as top prioritized solution for flood control followed by Q5, Q2, Q4 and Q1 respectively. The intended solution of raising embankments is least prioritized. The recommended solution lowers the flood peak by extracting discharge using an old course during the flood. Suitable regulating hydraulic structures of around 250 $\mathrm{m}$ to $300 \mathrm{~m}$ wide to open bifurcation channel need to be constructed in appropriate location along the old course. This measure reduces discharge in downstream resulting smaller loads in embankments. This helps people to be prepared and location of inundation in known. Additional construction of bridges along highway, additional construction of embankments along the old course, acquirement of large agriculture land, protection of bank erosion increases the implementation time with costs.

For sediment control measures, among nine combinations of criteria weighting and preference ranking methods, an alternate measure, reduction of upstream sediment supply (S1) is first prioritized with all combinations of criteria weighting techniques Entropy, AHP, AHP \& Entropy and preference ranking method SAW (Table 6). However, combination of two criteria weighting techniques Entropy and Entropy-AHP with preference ranking method TOPSIS results narrowing river by recurrent measures (S4) solution the highest priority over other alternatives. However, combination of criteria weighting methods AHP with preference ranking method TOPSIS orders reduction of upstream se- 
diment supply (S1) solution as paramount. Similarly, combination of each criteria-weighting techniques with preference ranking method ELECTRE provides different preference ranking. A combination of criteria weighting method Entropy and AHP with preference ranking method ELECTRE prioritizes two alternate solutions Koshi high dam (S2) and controlled flooding with deposition areas (S7) simultaneously as the highest ranks. Two alternate solutions narrowing river by recurrent measures (S4) and dredging (S5) are simultaneously prioritized the top ranks by combination of criteria weighting method Entropy with preference ranking method ELECTRE. Besides, combination of criteria-weighting technique AHP with preference ranking method ELECTRE ranks controlled flooding and sedimentation using old course (S6) in the first position over others. The results show deviations on preference ranking with different methods. This may be due to variations in criteria weighting index. Considering average value of results for all nine set of combinations of criteria weighting methods and preference ranking methods, an alternate solution prescribing reduction on upstream sediment supply ( $\mathrm{S} 1$ ) is recommended as top prioritized and removing embankments and Koshi barrage (S8) as the least prioritized measures for sediment control. The recommended top prioritized measure comprises bottom or bank protection; check dams and reforestation to decrease the supply of sediment at its origin. The processes which are responsible for the high sediment load of the river i.e. landslides, bank and bottom erosion and GLOFs, have to be reduced. However, its tedious job and takes long time to realize the results.

The recommended measures are also assessed against sustainability. Fairness, reversibility, risk and consensus are four conceptual criteria recommended by Simonovic [24] to satisfy the sustainability of all kinds of structural measures applied for flood risk management. Fairness provides a meaningful format for assessing the distribution of benefits. Risk has measurable qualities, provided the proper risk events are identified and the probabilities can be calculated. Reversibility evaluates the degree to which the aggregated set of anticipated or unanticipated impacts of a development project can be mitigated. Consensus describes the level in which stakeholders are satisfied with a solution to a problem under consideration. The recommended hydraulic measures of using old Koshi course for flood risk management and reduction of upstream sediment supply for sediment control are fair in distribution of benefits. Both the solutions have less risk with low probability of failure. Both measures meet the criteria of reversibility. There is less chance of dispute among stakeholders on implementation of the measures leading broader consensus.

The results of this study can be utilized by local authority as base line information for the structural measures for sustainable flood risk management and sediment control. On implementation of the recommended measures, local people of Saptari, Sunsari and Morang districts of Nepal will be highly benefited. The surrounding areas can be protected from inundation thus ensuring safety of 
local people. More agricultural lands can be reclaimed enhancing local people's economic condition. Moreover, the recommended measures protect the environment and using embanked old Koshi channel creates opportunity to flora and fauna as well.

\section{Sensitivity Analysis}

\subsection{Criteria Weighting Techniques}

\subsubsection{Spearman's Rank Correlation Coefficient}

The weighting indexes are estimated using Entropy, AHP and combination of Entropy and AHP methods. The correlation between these indexes is determined by Spearman's rank correlation coefficient. The Spearman correlation between two variables is equal to the Pearson correlation between the rank values of those two variables. If there are no repeated data values, a perfect Spearman correlation of +1 or -1 occurs when each of the variables is a perfect monotone function of the other. Intuitively, the Spearman correlation between two variables will be high when observations have a similar rank between the two variables, and low when observations have a dissimilar rank between the two variables. Mathematically, Spearman correlation coefficient $\left(\gamma_{s}\right)$ is computed as:

$$
\gamma_{s}=1-\frac{6 \sum d_{i}^{2}}{n\left(n^{2}-1\right)}
$$

where, $d_{i}=$ difference between the two ranks of each observation, $n=$ number of observation.

The results (Table 7) show that correlation coefficient for combination of criteria weighting techniques AHP with AHP-Entropy is very high (0.964). This suggests that the results of these two techniques are very close together and while the correlation between Entropy and AHP technique is much lower (0.321) indicating the lack of consistency in the results of those two techniques together. The t-test of Spearman's rank correlation coefficient in significance level $(\alpha)=$ 0.05 and degree of freedom $(n-2)=5$, correlates the weighting techniques establishing the correlation status (Table 8).

The correlation status shows that results of the two techniques, Entropy and AHP, are not correlated. In other words, the results of these techniques are very different from each other. On the other hand, the combination of weighting techniques AHP and AHP-Entropy possess high correlation showing the closer results. Moreover, a combination of Entropy and AHP-Entropy possess low correlation.

Table 7. Spearman's rank correlation coefficient.

\begin{tabular}{rc}
\hline Weighting technique & Spearman' rank correlation coefficient \\
\hline AHP and Entropy & 0.321 \\
Entropy and AHP-Entropy & 0.429 \\
AHP and AHP-Entropy & 0.964 \\
\hline
\end{tabular}


Table 8. Correlation status using t-test.

\begin{tabular}{cc}
\hline Correlation status & Weighting technique \\
\hline Lack of correlation & AHP and Entropy \\
Correlation & Entropy and AHP-Entropy \\
Correlation & AHP and AHP-Entropy \\
\hline
\end{tabular}

\subsection{Combined Weighting and Prioritization Techniques}

\subsubsection{Euclidean Distance}

Sensitivity analysis of the preference raking results is carried out determining and comparing Euclidean distance for each pairs of criteria weighting and prioritization techniques. Altogether 36 pairs are formed and Euclidean distance for each pair is determined (Table 9, Table 10). In this approach, calculated distance between two techniques shows degree of similarity between these techniques. If the calculated distance is less, there is more similarity between two techniques and vice-versa.

In Table $9 \&$ Table 10, values in the rows 18, 21 and 33 reflect stability of SAW method of preference ranking. Similarly, rows 11, 14 and 29 are related to TOPSIS and rows 3, 6 and 24 to ELECTRE. The results show that all three MCDM techniques of preference ranking ELECTRE, TOPSIS and SAW are not very stable and are sensitive to weighting.

\section{Conclusions}

Multi-criteria decision making approaches were applied to assess prioritization of technical measures for flood risk management and sediment control in Koshi alluvial fan. Criteria weighting indexes were estimated using weighting techniques Entropy, AHP and AHP-Entropy. Preference ranking of alternatives of technical measures was completed using multi-criteria decision making (MCDM) methods-ELECTRE, TOPSIS and SAW. Five alternate measures for flood risk management and eight alternate measures for sediment control with seven evaluation criteria comprising economic, social, political and environmental aspects were taken into account. The Spearman's rank correlation coefficient and t-test showed strong correlation between the criteria weighting techniques AHP and AHP-Entropy, weak correlation between Entropy and AHP-Entropy and no correlation between AHP and Entropy. Preference ranks were determined using nine combinations of criteria weighting techniques and preference ranking methods. Considering average value of results for all nine combinations, alternate measures were prioritized and recommended. In the case of flood risk management, among intended hydraulic measures, using of old Koshi channel was recommended as the highest prioritized and raising embankments, the least prioritized measure. Similarly, for sediment control, reduction of upstream sediment supply and removing embankments and Koshi barrage were recommended as top and least prioritized measures respectively. The Euclidean distance test for each pair of criteria weighting and prioritization 
Table 9. Euclidean distance for combined weighting and prioritization techniques (Hydraulic measures).

\begin{tabular}{cccccc}
\hline S.N & $\begin{array}{c}\text { Techniques } \\
\text { compared }\end{array}$ & $\begin{array}{c}\text { Euclidean } \\
\text { distance }\end{array}$ & S.N & $\begin{array}{c}\text { Techniques } \\
\text { compared }\end{array}$ & $\begin{array}{c}\text { Euclidean } \\
\text { distance }\end{array}$ \\
\hline 1 & (AE-E)-(AE-T) & 4.243 & 19 & (AE-S)-(AE) & 4.243 \\
2 & (AE-E)-(AE-S) & 4.472 & 20 & (AE-S)-(AT) & 2.000 \\
3 & (AE-E)-(EE) & 0.000 & 21 & (AE-S)-(AS) & 0.000 \\
4 & (AE-E)-(ET) & 4.243 & 22 & EE-ET & 4.243 \\
5 & (AE-T)-(ES) & 4.690 & 23 & EE-ES & 4.690 \\
6 & (AE-E)-(AE) & 2.000 & 24 & EE-AE & 2.000 \\
7 & (AE-E)-(AT) & 4.243 & 25 & EE-AT & 4.243 \\
8 & (AE-E)-(AS) & 4.472 & 26 & EE-AS & 4.472 \\
9 & (AE-T)-(AE-S) & 2.000 & 27 & ET-ES & 3.742 \\
10 & (AE-T)-(EE) & 4.243 & 28 & ET-AE & 3.162 \\
11 & (AE-T)-(ET) & 2.828 & 29 & ET-AT & 2.828 \\
12 & (AE-T)-(ES) & 4.243 & 30 & ET-AS & 3.464 \\
13 & (AE-T)-(AE) & 3.162 & 31 & ES-AE & 5.099 \\
14 & (AE-T)-(AT) & 0.000 & 32 & ES-AT & 4.243 \\
15 & (AE-T)-(AS) & 2.000 & 33 & ES-AS & 2.828 \\
16 & (AE-S)-(EE) & 4.472 & 34 & AE-AT & 3.162 \\
17 & (AE-S)-(ET) & 3.464 & 35 & AE-AS & 4.243 \\
18 & (AE-S)-(ES) & 2.828 & 36 & AT-AS & 2.000 \\
\hline
\end{tabular}

Table 10. Euclidean distance for combined weighting and prioritization techniques (Sediment control measures).

\begin{tabular}{|c|c|c|c|c|c|}
\hline S.N & $\begin{array}{l}\text { Techniques } \\
\text { compared }\end{array}$ & Euclidean distance & S.N & $\begin{array}{c}\text { Techniques } \\
\text { compared }\end{array}$ & Euclidean distance \\
\hline 1 & $(\mathrm{AE}-\mathrm{E})-(\mathrm{AE}-\mathrm{T})$ & 9.434 & 19 & (AE-S)-(AE) & 10.630 \\
\hline 2 & (AE-E)-(AE-S) & 11.358 & 20 & (AE-S)-(AT) & 5.831 \\
\hline 3 & $(\mathrm{AE}-\mathrm{E})-(\mathrm{EE})$ & 7.810 & 21 & (AE-S)-(AS) & 3.464 \\
\hline 4 & $(\mathrm{AE}-\mathrm{E})-(\mathrm{ET})$ & 9.950 & 22 & EE-ET & 7.746 \\
\hline 5 & $(\mathrm{AE}-\mathrm{T})-(\mathrm{ES})$ & 11.358 & 23 & EE-ES & 8.845 \\
\hline 6 & $(\mathrm{AE}-\mathrm{E})-(\mathrm{AE})$ & 4.899 & 24 & EE-AE & 8.307 \\
\hline 7 & (AE-E)-(AT) & 9.000 & 25 & EE-AT & 8.000 \\
\hline 8 & (AE-E)-(AS) & 10.440 & 26 & EE-AS & 8.718 \\
\hline 9 & $(\mathrm{AE}-\mathrm{T})-(\mathrm{AE}-\mathrm{S})$ & 5.831 & 27 & ET-ES & 4.899 \\
\hline 10 & $(\mathrm{AE}-\mathrm{T})-(\mathrm{EE})$ & 7.746 & 28 & ET-AE & 10.630 \\
\hline 11 & $(\mathrm{AE}-\mathrm{T})-(\mathrm{ET})$ & 1.414 & 29 & ET-AT & 2.449 \\
\hline 12 & (AE-T)-(ES) & 5.831 & 30 & ET-AS & 4.472 \\
\hline 13 & $(\mathrm{AE}-\mathrm{T})-(\mathrm{AE})$ & 10.344 & 31 & ES-AE & 10.360 \\
\hline 14 & $(\mathrm{AE}-\mathrm{T})-(\mathrm{AT})$ & 2.000 & 32 & ES-AT & 5.831 \\
\hline 15 & $(\mathrm{AE}-\mathrm{T})-(\mathrm{AS})$ & 4.899 & 33 & ES-AS & 3.464 \\
\hline 16 & $(\mathrm{AE}-\mathrm{S})-(\mathrm{EE})$ & 8.485 & 34 & $\mathrm{AE}-\mathrm{AT}$ & 9.950 \\
\hline 17 & (AE-S)-(ET) & 4.899 & 35 & AE-AS & 10.909 \\
\hline 18 & (AE-S)-(ES) & 0.000 & 36 & AT-AS & 4.690 \\
\hline
\end{tabular}


methods showed all three MCDM methods of preference ranking ELECTRE, TOPSIS and SAW were sensitive to weighting.

The results of this study can be utilized by local authority as base line information for the structural measures for sustainable flood risk management and sediment control. The methodology used in this study can be applied to other rivers having similar physical characteristics and dynamic alluvial fan. On implementation of the recommended measures, local people of Saptari, Sunsari and Morang districts of Nepal will be highly benefited. The study didn't incorporate non-structural measures of flood risk management including mapping vulnerable areas, changing cropping pattern and establishment of flood early warning system (FEWS) and recommended for further study.

\section{Acknowledgements}

This work is self-funded by the authors. It is a part of $\mathrm{PhD}$ program of correspondent author.

\section{Author Contributions}

Mukesh Raj Kafle was responsible for this current research article in the framework of his PhD program and initially wrote the manuscript. Narendra Man Shakya directed the study by helping to interpret the results and improving the quality of manuscript.

\section{Conflicts of Interest}

The authors declare no conflicts of interest.

\section{References}

[1] Hill, C.V. (1997) Environment and Social Control in Riparian North India 1770-1994: Asian Studies. Monograph and Occasional Paper Series, Number 55, 200 p.

[2] Meena, R.S. (2012) Simulation of Runoff and Flood Inundation in Kosi River Basin Using Hydrological Models, ANN, Remote Sensing and GIS. National Institute of Technology, Rourkela.

[3] Evert, H. (2011) Flooding and Sediment Management on the Koshi Alluvial Fan, Nepal. M.Sc. Thesis, Delft University of Technology, Delft.

[4] Voogd, H. (1983) Multicriteria Evaluation for Urban and Regional Planning. Pion Ltd., London, $367 \mathrm{p}$.

[5] Hwang, C.L. and Yoon, K. (1981) Multiple Attribute Decision Making: Methods and Applications. Springer-Verlag, New York. https://doi.org/10.1007/978-3-642-48318-9

[6] Choo, E.U., Schoner, B. and Wedley, W.C. (1999) Interpretation of Criteria Weights in Multi Criteria Decision-Making. Computers \& Industrial Engineering, 37, 527-541. https://doi.org/10.1016/S0360-8352(00)00019-X

[7] Yan, H., Bin Huynh, V.N. and Nakamori, Y. (2011) A Probabilistic Model for Linguistic Multi-Expert Decision Making Involving Semantic Overlapping. Expert Systems with Applications, 38, 8901-8912. https://doi.org/10.1016/j.eswa.2011.01.105 
[8] Pohekar, S.D. and Ramachandran, M. (2004) Application of Multi-Criteria Decision Making to Sustainable Energy Planning: A Review. Renewable \& Sustainable Energy Reviews, 8, 365-381. https://doi.org/10.1016/j.rser.2003.12.007

[9] Affeletranger, B. (2001) Public Participation in the Design of Local Strategies for Flood Mitigation and Control. International Hydrological Programme, Technical Documents in Hydrology No. 48, UN-ESCO, Paris.

[10] Tkach, R.J. and Simonovic, S.P. (1997) A New Approach to Multi-Criteria Decision Making in Water Resources. Journal of Geographic Information and Decision Analysis, 1, 25-43.

[11] Ghanbarpour, M.R., Salimi, S. and Hipel, K.W. (2013) A Comparative Evaluation of Flood Mitigation Alternatives Using GIS-Based River Hydraulics Modelling and Multi Criteria Decision Analysis. Journal of Flood Risk Management, 6, 319-331. https://doi.org/10.1111/jfr3.12017

[12] Malekian, A. and Azarnivand, A. (2015) Application of Integrated Shannon's Entropy and VIKOR Techniques in Prioritization of Flood Risk in the Shemshak Watershed, Iran. Water Resources Management, 30, 409-425.

https://doi.org/10.1007/s11269-015-1169-6

[13] Guo, et al. (2014) Integrated Risk Assessment of Flood Disaster Based on Improved Set Pair Analysis and the Variable Fuzzy Set Theory in Central Liaoning Province, China. Natural Hazards, 74, 947-965. https://doi.org/10.1007/s11069-014-1238-9

[14] Roy, D.C. and Blaschke, T. (2015) Spatial Vulnerability Assessment of Floods in the Coastal Regions of Bangladesh. Geomatics, Natural Hazards and Risk, 6, 21-44. https://doi.org/10.1080/19475705.2013.816785

[15] Yang, X.L., Ding, J.H. and Hou, H. (2013) Application of a Triangular Fuzzy AHP Approach for Flood Risk Evaluation and Response Measures Analysis. Natural Hazards, 68, 657-674. https://doi.org/10.1007/s11069-013-0642-x

[16] Mendoza, G.A. and Martins, H. (2006) Multi-Criteria Decision Analysis in Natural Resource Management: A Critical Review of Methods and New Modelling Paradigms. Forest Ecology and Management, 230, 1-22. https://doi.org/10.1016/j.foreco.2006.03.023

[17] Margeta, J. and Knezic, S. (2002) Selection of the Flood Management Solution of Karstic Field. Water International, 27, 431-441. https://doi.org/10.1080/02508060208687022

[18] Lee, K.S. and Chung, E.S. (2007) Development of Integrated Watershed Management Schemes for an Intensively Urbanized Region in Korea. Journal of $\mathrm{Hy}$ dro-Environment Research, 1, 95-109. https://doi.org/10.1016/j.jher.2007.07.004

[19] Zhou, Z., Wang, X., Sun, R., Ao, X., Sun, X. and Song, M. (2014) Study of the Comprehensive Risk Analysis of Dam-Break Flooding Based on the Numerical Simulation of Flood Routing. Part II: Model Application and Results. Natural Hazards, 73, 675-700. https://doi.org/10.1007/s11069-013-1029-8

[20] Gohain, K. and Parkash, B. (1990) Morphology of the Kosimegafan. University of Roorkee, Roorkee.

[21] Roy, B. (1968) Classementetchoix en présence de points de vue multiples. Recherche Opérationnelle, 2, 57-75.

[22] Velasquez, M. and Hester, P. (2013) An Analysis of Multi-Criteria Decision Making Methods. International Journal of Operations Research, 10, 56-66.

[23] Churchman, C.W. and Ackoff, R.L. (1954) An Approximate Measure of Value. Operations Research Society of America, 2, 172-187. 
https://doi.org/10.1287/opre.2.2.172

[24] Takeuchi, et al. (1998) Sustainable Reservoir Development and Management. IAHS Publication No. 251. 